\title{
Validating "announcer" and "confessor" styles of mental health self-disclosure through use of archived qualitative data
}

\author{
Nicola L. Coe \\ Research \& Innovation, North Bristol NHS Trust, Bristol, UK; nicolawilliams6@nhs.net
}

Received 15 January 2013; revised 20 February 2013; accepted 27 February 2013

\begin{abstract}
Two new conceptual styles of self-disclosure were identified in a previous study-"announcers" and "confessors". The styles and characteristics of each had been derived from disclosures made during Somerset Health Panel discussions in 2001 on attitudes to stress and depression. The aim of this article is to validate and refine the concepts of "announcer" and "confessor" styles of self-disclosure. Data from archived qualitative data of seven focus groups collected in 2006 for the Cultural Context of Youth Suicide study was analysed. The results validated the concept of two styles of self-disclosure (announcers and confessors) and highlight additional factors that impact on disclosure. This study adds new insights in how people disclose personal or sensitive information and the impact of specific factors (contextual, individual and methodological) on the disclosure style used. Importantly, this article also demonstrates that qualitative data can be reused successfully in the development of models in communication and social interaction theory.
\end{abstract}

Keywords: Self-Disclosure; Qualitative Research; Mental Health; Announcers; Confessors

\section{INTRODUCTION}

In the broadest sense, the primary goal of any focus group is to encourage self-disclosure [1]; to encourage people to talk about their thoughts and feelings on a given topic. Focus groups are used for a range of purposes and discussion of sensitive topics is one. Selfdisclosures in this context can be defined as "personal revelations of thoughts or actions that were often painful to the speaker and that risked censure because they were contrary either to family or social mores or to their role expectations" [2]. Two new conceptual styles of self-disclosure were identified in a previous study-“announcers" and "confessors" [3]. The characteristics of each, as summarised in the previous article, are shown in Figure 1.

A number of key factors that facilitate self-disclosure in focus groups were found to be consistent with other research, e.g. establishing common ground, breaking the ice, humour and setting the tone [4-8]. However, it was identified in the previous study [3] that there were differences between "announcers" and "confessors" responses to these factors, with confessors more likely to be influenced by them than announcers.

The development of the concept of two styles was derived through analysis of data collected during the Somerset Health Panels discussion in 2001 on "attitudes to stress, depression and help-seeking” [9]. The Somerset Health Panels were a distinct and established focus group based method of public involvement established in Somerset (South West England) in 1994 to obtain local people's views about health issues [10-12]. The importance of disclosure relating to mental health problems is

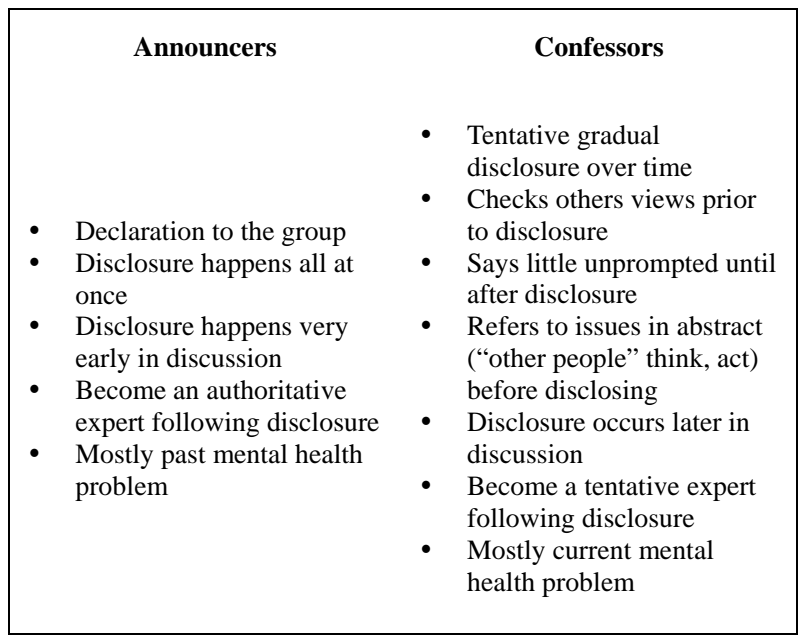

Figure 1. Characteristics of announcers and confessors found in Somerset Health Panels disclosures [3]. 
particularly significant as research demonstrates that disclosure is a key barrier to help-seeking [9]. Evidence on the effectiveness of measures to then improve mental health and help-seeking is the focus of much of the mental health literature, although "mental health literacy" is considered by many to be key for both those seeking help and those supporting others to seek help $[13,14]$.

The health panel method created an environment where participants were able to disclose personal and sensitive stories and demonstrates that health panels can be used successfully for the discussion of sensitive topics [12]. Although health panels share many of the characteristics of focus groups (i.e. they are groups of people, brought together for a focused purpose, facilitated by a moderator, and discussion is recorded, transcribed and analysed) it is unknown if different types of focus groups or certain interviewing techniques (such as use of vignettes) facilitate the same styles of self-disclosure. It is important when developing a new concept to consider these issues and therefore conducting further analysis using other data to validate the previously identified "announcer" and "confessor" styles is essential.

Secondary analysis of qualitative data has been made accessible to researchers through the establishment of the Economic and Social Data Service (ESDS) Qualidata as part of the UK data archive. This is supported by the Economic and Social Research Council (ESRC) data policy, which requires all ESRC grant award holders to offer their data to the archive. The aim of this article is to test if announcer and confessor self-disclosure styles can be validated and refined through the reuse of such archived data.

\section{METHODS}

\subsection{Design}

This article presents the results of a contemporary analysis of archived focus group data collected in 2006 for the "The Cultural Context of Youth Suicide: Identity, Gender and Sexuality" study. This study included 11 focus groups and 13 interviews with participants aged 16 25 years. Seven focus groups were held in the North of England and four in South Wales, involving a total of 66 young people. Descriptive statistics in Table 1 summarise the focus group composition for the Youth Suicide study compared to the Somerset Health Panels.

Table 1. Participant/focus group composition.

\begin{tabular}{|c|c|c|c|c|c|c|c|c|c|c|c|c|}
\hline \multirow{2}{*}{ Dataset } & \multirow{2}{*}{ Area } & \multirow{2}{*}{ Group } & \multirow{2}{*}{$\begin{array}{c}\begin{array}{c}\text { Total } \\
\text { participants }\end{array} \\
\text { No }\end{array}$} & \multicolumn{2}{|c|}{ Male } & \multicolumn{2}{|c|}{ Female } & \multicolumn{2}{|c|}{$\begin{array}{l}\text { Disclosed MH } \\
\text { problem }\end{array}$} & \multicolumn{2}{|c|}{ Announcers } & \multirow{2}{*}{$\begin{array}{l}\text { Original data } \\
\text { reference }\end{array}$} \\
\hline & & & & No & $\%$ & No & $\%$ & No & $\%$ & No & $\%$ & \\
\hline \multirow{4}{*}{$\begin{array}{c}\text { Somerset } \\
\text { Health Panels }\end{array}$} & Somerset & A & 7 & 2 & $29 \%$ & 5 & $71 \%$ & 3 & $43 \%$ & 1 & $33 \%$ & A2001a \\
\hline & Somerset & B & 9 & 3 & $33 \%$ & 6 & $67 \%$ & 2 & $22 \%$ & 1 & $50 \%$ & A2001c \\
\hline & Somerset & $\mathrm{D}$ & 7 & 3 & $43 \%$ & 4 & $57 \%$ & 1 & $14 \%$ & 1 & $100 \%$ & A2001g \\
\hline & Somerset & $\mathrm{E}$ & 8 & 4 & $50 \%$ & 4 & $50 \%$ & 1 & $13 \%$ & 1 & $100 \%$ & A2001h \\
\hline \multicolumn{3}{|c|}{ Total (Somerset Health Panels) } & 38 & 16 & $42 \%$ & 22 & $58 \%$ & 9 & $24 \%$ & 5 & $56 \%$ & \\
\hline \multirow{9}{*}{$\begin{array}{c}\text { Cultural } \\
\text { context of } \\
\text { youth } \\
\text { suicide study }\end{array}$} & South Wales & $\mathrm{F}$ & 3 & 2 & $67 \%$ & 1 & $33 \%$ & 2 & $67 \%$ & \multirow[t]{3}{*}{1} & \multirow[t]{3}{*}{$50 \%$} & 6063fg11 \\
\hline & South Wales & & 7 & 7 & $100 \%$ & 0 & $0 \%$ & 0 & $0 \%$ & & & $6063 f g 07$ \\
\hline & South Wales & & 6 & 0 & $0 \%$ & 6 & $100 \%$ & 0 & $0 \%$ & & & $6063 f g 09$ \\
\hline & North England & G & 3 & 0 & $0 \%$ & 3 & $100 \%$ & 2 & $67 \%$ & \multirow[t]{2}{*}{1} & \multirow[t]{2}{*}{$50 \%$} & $6063 f g 02$ \\
\hline & North England & & 2 & 0 & $0 \%$ & 2 & $100 \%$ & 0 & $0 \%$ & & & $6063 f g 08$ \\
\hline & North England & $\mathrm{H}$ & 12 & 4 & $33 \%$ & 6 & $50 \%$ & 3 & $25 \%$ & 3 & $100 \%$ & $6063 f g 10$ \\
\hline & North England & $\mathrm{I}$ & 6 & 3 & $50 \%$ & 3 & $50 \%$ & 5 & $83 \%$ & 3 & $60 \%$ & $6063 f g 03$ \\
\hline & North England & $\mathrm{J}$ & 9 & 2 & $22 \%$ & 7 & $78 \%$ & 1 & $11 \%$ & 1 & $100 \%$ & $6063 f g 04$ \\
\hline & North England & $\mathrm{K}$ & 7 & 2 & $29 \%$ & 5 & $71 \%$ & 2 & $29 \%$ & 1 & $50 \%$ & $6063 f g 05$ \\
\hline \multicolumn{3}{|c|}{ Total (Cultural context of youth suicide) } & 4 & 4 & $100 \%$ & 0 & $0 \%$ & 0 & $0 \%$ & & & $6063 f g 06$ \\
\hline
\end{tabular}




\subsection{Data}

Original transcripts from "The Cultural Context of Youth Suicide: Identity, Gender and Sexuality” study were obtained via the UK Economic and Social Data Service (ESDS) [15]. No research ethics approval was required for the secondary analysis as data in the archive is anonymised and subject to the ESDS end user license terms and conditions. Approval was obtained from Lancaster University Research Ethics Committee and consent obtained from participants by the researchers when the data was originally collected.

These data were selected for this study as: the discussion topic was similar to the original Somerset Health Panel discussion; the data had been collected from other parts of the UK; and it involved different age groups. The Youth Suicide study explored how young people think about suicide and self-harm and specifically how young people's understandings of how distress relating to gender identity or sexuality could lead to suicide. The researchers found that young people view suicide as accessible and rational, and that self-harm was used and perceived as a common coping strategy by young people $[16,17]$. The researchers did not specifically explore the way in which disclosures of self-harm and suicidal behaviour were made by the participants.

\subsection{Analysis}

All eleven focus group transcripts were reviewed to identify those that contained mental-health related selfdisclosures, i.e. self-disclosure of personal history of selfharm, suicidal intention, depression or other mental health problems. Those transcripts that were found to include one or more mental health related self-disclosure were then reviewed in more detail using a deductive framework analysis approach [18] to determine if the style of disclosures compared to those identified through analysis of the Somerset Health Panel data. This was performed by coding the data using the framework and specifically the disclosure part of the coding structure derived from the inductive analysis of the Somerset Health Panel data.

NVivo8 was used to facilitate data management and analysis. Two colleagues also reviewed two of the same transcripts and discussion regarding coding and interprettation ensured validity of analysis. For each quote used within this article a reference is provided to the focus group and participant-i.e. “A3” refers to focus group A, participant 3 . In addition, the archive data reference is provided in Table 1.

\section{RESULTS}

Six out of the eleven Youth Suicide study focus groups included at least one mental health related self-disclosure.
The self-disclosure rate was similar to the Somerset Health Panels, with 15/66 (23\%) of participants self-disclosing a history of depression, self-harm or suicidal intention (Table 1).

The two distinct styles of announcers and confessors and their relative characteristics were identifiable within the Youth Suicide data. In both datasets, overall there were more announcers than confessors, with the proportion of announcers slightly higher in the Youth Suicide study (although numbers are too small to test if this is a significant difference). For example announcer K3 disclosed their self-harming behaviour without prompting from others or any preceding general statements to gauge the attitudes of others:

I've [cut myself] since I was like 6 so it's just kind of routine now...I don't sleep and I don't eat very often so to get rid of the anxiety feeling I cut myself...the scientific fact for it is when you cut yourself it releases endorphins, when it releases endorphins you stop thinking about the anxiety you are feeling in your stomach...I've been doing it for 11 years and I know how to do it and I'm quite, very safe with it.

Consistent with the previous findings, K3 announces they self-harm then immediately transitions in the latter half of the excerpt from the disclosure into a more confident contribution-and later in the transcript takes a role as self-appointed "expert", making statements regarding background science and generalising from their own experience.

Throughout the discussions there were also numerous examples of non-mental health related self-disclosures. The discussion topics covered by the groups included sexual preferences and risk taking behaviours (drinking and taking drugs). Self-disclosures were made about all of these by many of the participants. Most of these disclosures were also announced in a direct way and it was clear that the group were not inhibited about talking about these issues in front of others (the facilitator or their peers).

In Figure 2 an announcement of drug use by participant I3 is clearly not affected by the potentially inhibiting comments made by others in the group. A number of participants made multiple disclosures during the discussion. Where this occurred, in all but one case each disclosure by the same participant followed a similar styleas either announcer (Figure 3) or confessor (Figure 4).

In the first example (Figure 3), the announcer (G2) discloses both self-harm and suicidal intent at different stages in the discussion without any prompting. In comparison, as found in the Somerset Health Panel data, the pathway for the confessor (I4) is more complex, where negative statements from others delay disclosure, and where they check what reactions might be with more general abstract statements prior to the disclosure (Fig- 


I: ..How do you think, if people have behaved
like that in kind of say in this college how
do you think people view them. You know if
they seem to be doing a lot of drug taking?
12: They just can't be assed doing anything it's
just like it becomes part of their life, they're
taking it to such an extent that nothing else
really matters and it's just it's just them
and whatever they're taking and that's it. It
becomes really isolated and away from
everybody and everything
Paranoid sometimes um one of my friends
got quite violent with it and you just have
to be careful when you're near them and try
not to annoy them or they'll go crazy
Sometimes yes but I mean I take drugs
sometimes and I wouldn't say I'm a crazy
or paranoid person you know, I do it in,
that I'm smart enough to know my limits
and that ...

Figure 2. Disclosure of drug use (Announcer).

G2: I actually, it's not my opinion but I think the large majority of people would be like $P$ [in vignette] just doing it for attention I think that's, everyone just

I: What's your personal opinion that you think

G2: Um I, I have experience of self harm myself so that, obviously this isn't my opinion but um

$<$ discussion by the group about attitudes to self-harm>

G2: Quite a lot of people I think, not me personally, but people who self harm think of their scars as like battle wounds whatever and they like to show them off cause it shows they've come through something or something like that where's some you know you must just think oh you know I don't really want to see them when I'm eating or

$<$ discussion by the group about others who have committed suicide>

G2: I think, I don't know if I'm going off the point but quite a lot of the time

Disclosure - Announcer

I mean in the past

Disclosure - Announcer I have thought about killing myself...

Figure 3. Multiple disclosures by announcer (G2)—self-harm and suicidal intent.

ure 4). In both examples, although the first disclosure related to self-harm and the second to suicidal intent, this may be due to the order of the topic guide rather than a natural order. In all cases, as found in the Somerset Health Panel data and as can be seen in the examples above (K3, G2, I4), the discloser (announcer or confessor) then subsequently contributes more confidently, taking on the self-appointed role of "expert" on that topic for the remainder of the discussion.

The exception to the pattern of consistent disclosure 


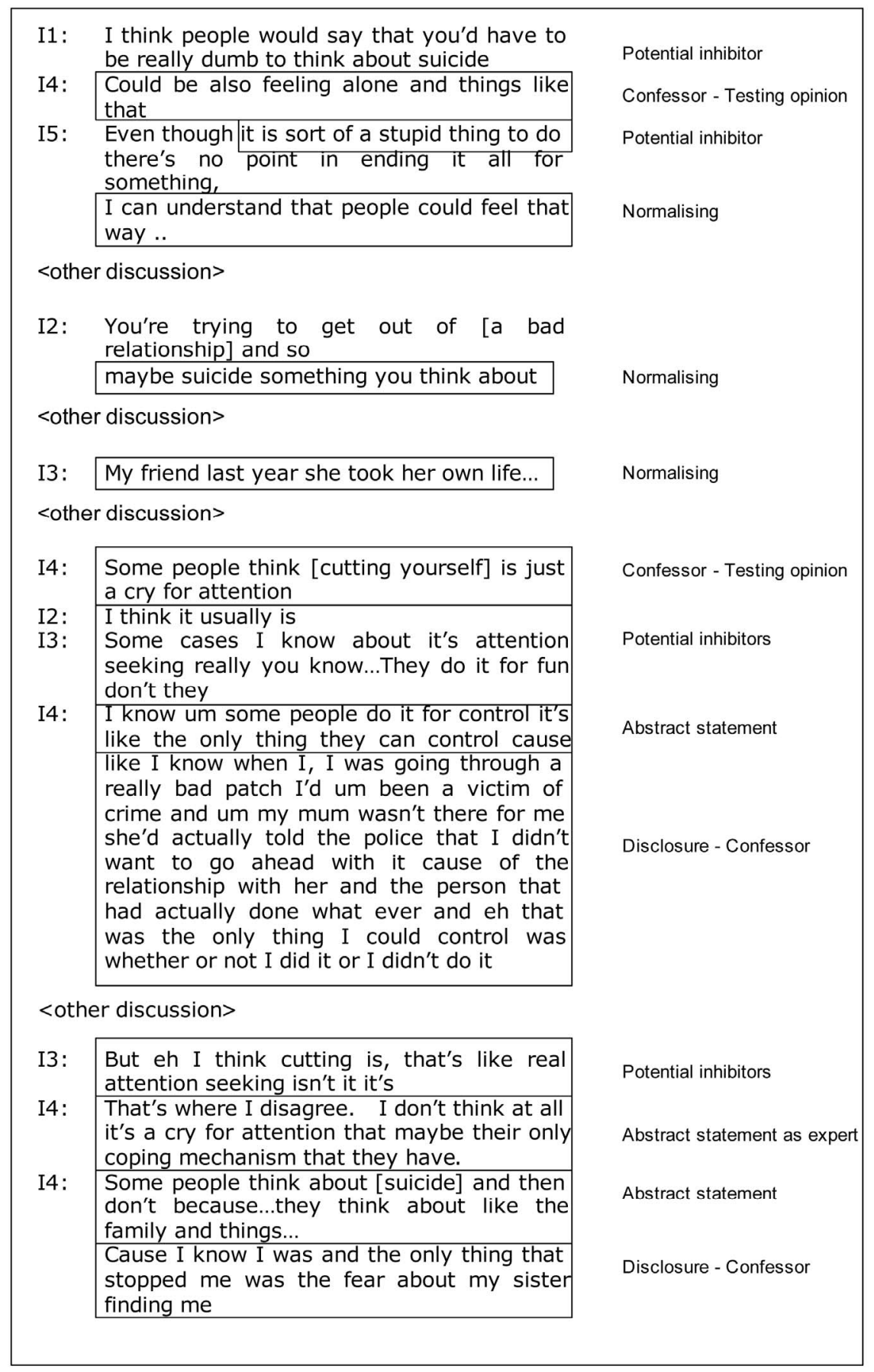

Figure 4. Multiple disclosures by confessor (I4)—self-harm and suicidal intent.

styles above is one instance where an announcer (K3) who had previously disclosed a history of self-harm switches disclosure style to confessor for a disclosure of sexual abuse later in the discussion (Figure 5).

The disclosure of sexual abuse displays confessor characteristics of moving along a pathway of abstract-personal-abstract statements. The use of these transition statements means that the discussion is diverted to a more general level. However, they do not seek reassur- ance from the group like other confessors, perhaps as they have already gauged reactions during their previous announcement.

There were a number of instances where a participant made a disclosure to the facilitator but it was clear from the discussion that they had previously made the same disclosure to others in the group. For example in Figure 6, participant J5 announces they self-harm to the group although this had clearly been previously disclosed to 
My friend has poured some kind of bleach on her hands and her arms, it burns your skin off.... met her through,

cause I was sexually abused when I was younger, I met her through this um like counselling thing cause she was sexually abused by her brother and her thing was similar to mine why I started doing it

if I hurt myself to such an extent he won't do it anymore because I won't be pretty anymore.

<other discussion not referring to disclosure>

My mum found out 3 weeks ago about

me being raped when I was younger

because she saw my arm and she wanted an explanation and I got so angry with her that I told her

but the reason why I didn't tell and the reason why dozens of my friends don't tell anybody is because you don't want your parents to think it's their fault and even if it is their fault you still don't want them to think that so you just don't say anything.
Partial disclosure

Transition statement - between self and someone else

Collective statement - self and someone else

Disclosure

Transition statement - between self and abstract

Collective statement - self and someone else

Figure 5. Confession by announcer (K3).

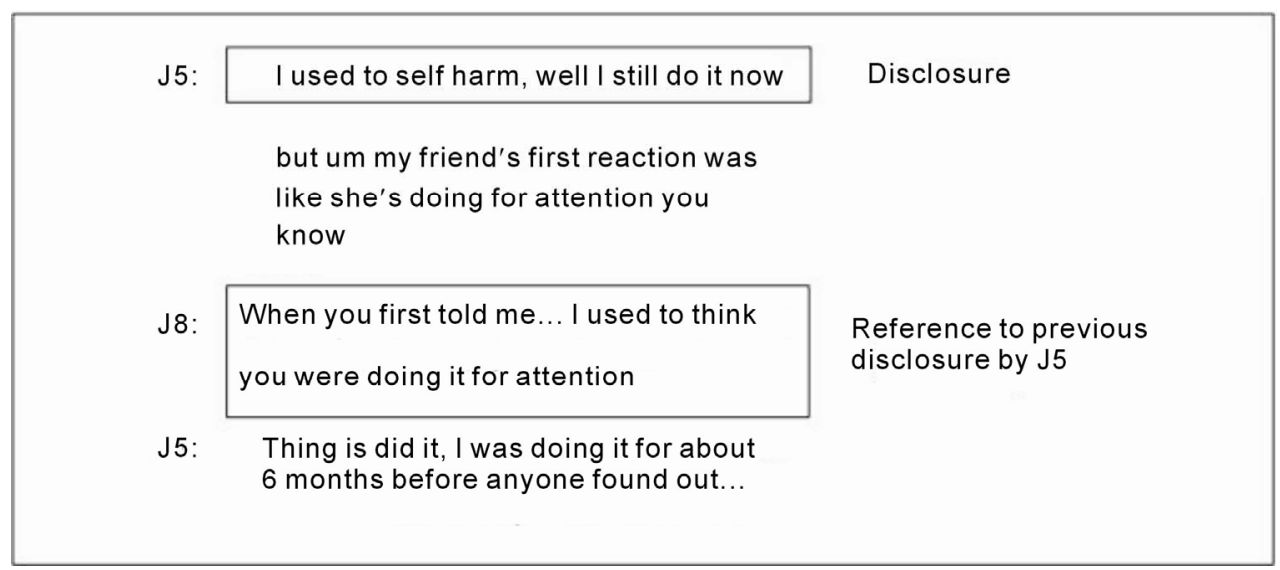

Figure 6. Prior disclosure.

participant J8.

In these cases, although they were disclosing for the first time to the facilitator and perhaps to other members of the group, they had the knowledge of how their friend had previously responded to the disclosure. For those participants who were "announcers" in this context, it is unknown whether they modified their style in other contexts, for example when they first disclosed to their friend in the group or the first time they ever disclosed this information.

In most groups, the majority of participants had examples of people they knew who self-harmed and most groups discussed at least one personal experience of someone else that had taken their own life. Although this was also the case in the Somerset Health Panel data, it was much more frequent in the Youth Suicide groups. Many noted that self-harm in particular was "normal" and often viewed by others as a "badge of honour". For example, one participant (F1) describes how her scars were viewed as such:

I have scars, I've got old scars here, here, here. ...the other day...I was in a model agency... and the make up artist she said "nice scars" ... and she's like did you do them yourself and I'm like yea, you know, I was a fucked up kid and I was like really embarrassed about it...but she was like oh that's cool.

In another group, three participants in the same group separately announce a suicide attempt or intent:

H2: Well I did attempt that once but it just didn't work

H11: Basically, I have tried it a lot of times and the 
only reason I'm here is "cause it failed"...

H3: But until then the only reason I didn't kill myself is because when I got bullied I started taking drugs...

The behaviour in these examples is normalised further by the disclosures of others. In many of the groups selfharming was viewed as an extremely common occurrence, and in the second set of examples the behaviour is normalised through three self-disclosures early in the discussion, providing reassurance to any of the other participants who subsequently disclosed.

\section{DISCUSSION}

The concept of two styles of self-disclosure, announcers and confessors and their relative characteristics are clearly evident in both the Somerset Health Panels [3] and Youth Suicide data. In both datasets announcers selfdisclosed with minimal prompting or inhibition and once disclosed, contributed confidently about their experiences during the subsequent discussion. Previously identified characteristics of confessors were also evidentthe use of abstract-personal-abstract pathways and use of statements to "test the water" prior to disclosure.

However, this study further refines the prior concept of two styles of self-disclosure into a model (Figure 7), providing insight into the relationship between these two self-disclosure styles and the factors that may indicate which style is used by the discloser.

The model proposes that the style of disclosure is influenced by a combination of individual plus group variables-i.e. previous disclosure (self or others), prior acquaintance, previous style (self/others), previous response/ reactions to self-disclosure or others, and the structure of the discussion. These variables can be perceived or actual-i.e. reaction can be what the participant anticipates the reaction would be or has actually experienced.

The two styles of disclosure might be distinct traits for some people, i.e. for any disclosure in any context a person always demonstrates one or other style; disclosure type is influenced by only the individual factors. More likely, a baseline trait style of disclosure will be influenced by their primary experience and the other factors (at an individual and group level).

Social Exchange Theory [19] underpins this proposal -that disclosure will occur if the perceived benefits outweigh the risks. From this analysis, it is indicated that risks may influence the style of disclosure and that the discloser combines these risk factors into a psychological equation that they may calculate and continuously recalculate as the context changes to determine if the risk of making a disclosure is worth taking. However, the interplay between risks is complex. For example, a first disclosure is obviously high risk as the discloser will be uncertain how others may respond. First disclosure might be the first time a particular person has ever made the disclosure (individual risk) and/or the first time they have made that specific disclosure to the others present (group risk) or a combination of the two. The baseline disclosure trait of that person (individual context) may be as an announcer but it is changed by the high risks associated with the disclosure within that context. They may therefore disclose in a confessor style but as that disclosure is repeated to others, subsequent disclosures are announced as confidence increases. Alternatively, as seen in the multiple disclosures of one participant in this study, a person may announce some disclosures and confess others to the same group depending on how "normal" they perceive the activity to be within that group, demonstrating a continual assessment of the risks of each disclosure. Social exchange theory assumes that risk balanced against the benefits realised such as emotional comfort, intimacy, material/financial gain. However, it is less obvious in this context what benefits are being realised for the individual and more broadly why people disclose at all. Personal benefits may be also emotional comfort, to seek to normalise their views or group or individual satisfaction that they have made a useful contribution to the discussion. Why people disclose sensitive information about themselves in a group situation and what benefits that brings them clearly warrants further research.

Specific individual variables such as age of participants (and other social or demographic variables) may have been interesting to explore, however this information was not collected during the Somerset health panels or available from the Youth Suicide study data. The impact of prior acquaintance also warrants further explora-
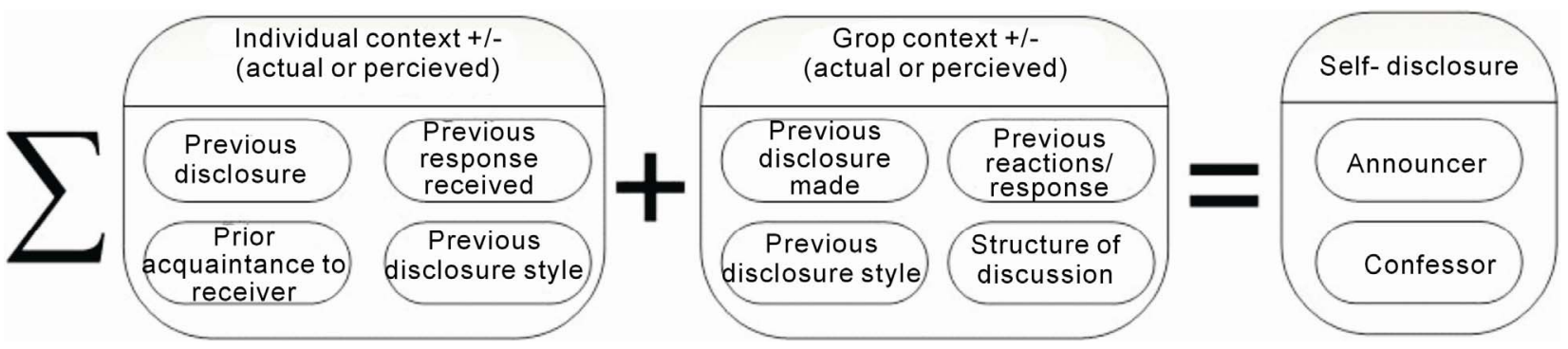

Figure 7. Factors affecting self-disclosure style. 
tion as whilst it could be inferred from the Youth Suicide transcripts that many participants knew each other already (through references to previous conversations they had had outside of the group) again comprehensive data was not available to determine the extent of this. Prior acquaintance is often reported as a key consideration focus group design [20]. Few Somerset Health Panel participants knew each other unlike those in the Youth Suicide groups, and therefore participants in the Somerset Health Panels might be less likely to anticipate what reactions were going to be prior to disclosure (increasing the group risk factor). One hypothesis is this may increase the likelihood of confessions over announcements rather than hindering disclosure, altogether the rate of disclosure between both groups overall appears similar as does the proportion of announcers to confessors (although numbers are too small to analyse statistically) so this does not support this hypothesis. What this does highlight however, is that the facilitator might need to be more adept at identifying when partial disclosures are made in groups comprising people who do not know each other.

An additional methodological consideration is in the structure and order of discussion. In the Youth Suicide Study vignettes and graffiti boards were used which directed the discussion to an abstract and generalised level. This did not appear to hinder disclosure as many participants moved discussion back to a personal level. The use of vignettes and graffiti boards in the Youth Suicide study made discussion about sensitive topics more comfortable for some participants, and they were used flexibly as a tool to generate discussion rather than to rigidly structure the discussion. These techniques weren't used in the Somerset Health Panels and disclosure rates do not suggest this had an impact. Therefore, providing they are not used rigidly and reduce the time focusing on personal attitudes and disclosure, techniques such as vignettes or graffiti boards clearly can be a useful technique to encourage participation in a focus group. However this does indicate researchers should consider how the design of the focus group has potential to impact on likelihood of self-disclosure. Focus groups should provide the opportunity for participants to explore issues in abstract and encourage discussion about "other" people as these are important pre-disclosure stages, but also that the facilitator should provide openers to allow the participants to move discussion onto a personal level.

There is considerable debate about the challenge of reuse or secondary analysis of qualitative data, much of which focuses on problems relating to the loss of context $[21,22]$. Some suggest that many view the central problem associated with reuse of qualitative data is that the relationship between the researcher and the context during data collection is missing when data is reused by others [23]. In this study, demographic information was also lacking but aspects of the context could still be inferred. Although not explicitly or systematically collected, it was still clear from the transcripts that some participants were already friends or had previously disclosed to others in the group and although this may require further research, this was included as a variable in the model developed as a result of the analysis undertaken.

Whilst the concept could have been refined from the original dataset, the need to validate in other datasets would have still been required-therefore to either collect new or reuse existing data would have been necessary. The development from a concept of two styles of disclosure to refinement of that concept into a model and validation of the original concept through the reuse of quailtative data from another study presents a cost effective and efficient use of data.

\section{CONCLUSION}

The concept of two styles of self-disclosure, announcers and confessors, was validated in this study. This article refines that concept into a model for how a variety of factors (risks and contexts) not only hinder or facilitator disclosure but also how they impact on the style by which people disclose personal or sensitive information about themselves. This study also identifies some important considerations for researchers when designing focus group based research in how to facilitate self-disclosure. Finally, this article demonstrates how qualitative data can be reused successfully and the value of accessible and appropriately archived qualitative data on theory building and the development of models of communication and social interaction.

\section{ACKNOWLEDGEMENTS}

This research included data from The Cultural Context of Youth Suicide study, funded by Economic and Social Research Council (Grant RES000221239), supplied by the UK Data Archive and permission for use granted to the author by K. Roen (28 July 2010). The original data creators, depositors or copyright holders, the funders of the Data Collections and the UK Data Archive bear no responsibility for their further analysis or interpretation.

I acknowledge Dr. David Evans and Dr. Maz Morris for their support and discussion in the development of this article.

\section{REFERENCES}

[1] Krueger, R.A. and Casey, M.A. (2000) Focus groups: A practical guide for applied research. Sage Publications Inc, Thousand Oaks.

[2] Williams, J.K. and Ayres, L. (2007) “I'm like you”: Establishing and protecting a common ground in focus groups 
with Huntington disease caregivers. Journal of Research in Nursing, 12, 655 doi:10.1177/1744987107083514

[3] Coe, N. (2013) Announcers and confessors: How people self-disclose depression in health panels. Health, 5, 79-88. doi:10.4236/health.2013.51011

[4] Hollander, J.A. (2004) The social contexts of focus groups. Journal of Contemporary Ethnography, 33, 602-637. doi:10.1177/0891241604266988

[5] Kitzinger, J. (1995) Qualitative research: Introducing focus groups. British Medical Journal, 311, 299-302. doi:10.1136/bmj.311.7000.299

[6] Hyden, L.-C. and Bulow, P.H. (2003) Who's talking: Drawing conclusions from focus groups-some methodological considerations. International Journal of Social Research Methodology, 6, 305-321. doi:10.1080/13645570210124865

[7] Frith, H. (2000) Focusing on sex: Using focus groups in sex research. Sexualities, 3, 275-297. doi:10.1177/136346000003003001

[8] Wilkinson, C.E., Rees, C.E. and Knight, L.V. (2007) From the heart of my bottom: Negotiating humor in focus group discussions. Qualitative Health Research, 17, 411-422. doi:10.1177/1049732306298375

[9] Coe, N. (2009) Exploring attitudes of the general public to stress, depression and help seeking. Journal of Public Mental Health, 8, 21-31. doi:10.1108/17465729200900005

[10] Bowie, C., Richardson, A. and Sykes, W. (1995) Consulting the public about health service priorities. British Medical Journal, 311, 1155-1158. doi:10.1136/bmj.311.7013.1155

[11] Department of Health (2008) Real involvement: Working with People to improve health services. Crown Copyright, London.

[12] Coe, N. (2012) Health Panels: The development of a meaningful method of public involvement. Policy Studies, 33, 263-281 doi:10.1080/01442872.2012.694267

[13] Coe, N.L. (2009) Critical evaluation of the Mental Health Literacy conceptual framework using qualitative data. In- ternational Journal of Mental Health Promotion, 11, 34 44. doi:10.1080/14623730.2009.9721798

[14] Jorm, A.F., Korten, A.E., Jacomb, P, A., Christensen, H., Rodgers, B. and Pollitt, P. (1997) "Mental Health Literacy": A survey of the public's ability to recognise mental disorders and their beliefs about the effectiveness of treatment. Medical Journal of Australia, 166, 182-186.

[15] Roen, K., Scourfield, J. and McDermott, E. (2008) Cultural context of youth suicide: Identity, gender and sexuality. UK Data Archive, Colchester.

[16] Roen, K., Scourfield, J. and McDermott, E. (2008) Making sense of suicide: A discourse analysis of young people's talk about suicidal subjecthood. Social Science \& Medicine, 67, 2089-2097. doi:10.1016/j.socscimed.2008.09.019

[17] Scourfield, J., Roen, K. and McDermott, L. (2008) Lesbian, gay, bisexual and transgender young people's experiences of distress: Resilience, ambivalence and selfdestructive behaviour. Health \& Social Care in the Community, 16, 329-336. doi:10.1111/j.1365-2524.2008.00769.x

[18] Braun, V. and Clarke, V. (2006) Using thematic analysis in Psychology. Qualitative Research in Psychology, 3, 77-101.

[19] Thibaut, J.W. and Kelley, H.H. (1959) The social psychology of groups. John Wiley \& Sons, New York.

[20] Morgan, D.L. (1995) Why things (sometimes) go wrong in focus groups. Qualitative Health Research, 5, 516-523. doi:10.1177/104973239500500411

[21] Moore, N. (2007) (Re)Using qualitative data? Sociological Research Online, 12. doi:10.5153/sro.1496

[22] Heaton, J. (2004) Reworking qualitative data. Sage, London.

[23] Moore, N. (2006) The context of context: Broadening perspectives on reuse. Methodological Innovations Online, 1.

http://erdt.plymouth.ac.uk/mionline/public_html/viewarti cle.php?id=27\&layout=html 